\title{
Wild-Spikenard (H. Suaveolens) Re-Invasion Pattern in Tropical Semi-Arid Environment Due to Distance from Filed-Edge-A Pilot Study
}

\author{
Tuhin Subhra Konar \\ Jadavpur University, Kolkata, West Bengal, India \\ Subhajit Paul (Corresponding author) \\ Bankura Sammilani College, Bankura 722102, West Bengal, India \\ E-mail: spaul.bios@gmail.com
}

Received: August 23, 2012 Accepted: September 16, 2012 Published: December 31, 2012

doi:10.5296/jee.v3i1.2288ＵRL: http://dx.doi.org/10.5296/jee.v3i1.2288

\begin{abstract}
The study of re-invasion of Hyptis Suaveolens has been conducted in two plots of tropical semi- arid environment of India in the district of Bankura, West Bengal. The two plots were eradicated of Hyptis in 2007 and data of counts were collected in every succeeding years until 2010, when populations reach a level prior to 2007. The data collected in quadrates were finally reduced to horizontal and vertical strip totals respectively, for each years. A hypothetical factor named Unified Field Edge Factor (UFEF) has been used to account the effects of field edge and field-side anthropogenic activities on distribution pattern of Hyptis. Regression equations have been developed for estimating population at different distances from UFEF. Spatial variation has further been addressed through Fourier frequency analyses and mutual correlation analyses of horizontal and vertical strip totals of Hyptis populations in different years. It was revealed that the pattern of spatial variation remain almost regular, although the total populations of Hyptis scaled up every year after eradication until it reach a saturation value almost alike that prior to the same.
\end{abstract}

Keyword: Anthropogenic activity, Field Edge, Hyptis suaveolens, Fourier transform, Weed invasion 


\section{Introduction}

The weed invasion in a region depends upon different prevailing natural and man made circumstances. It was mentioned by different workers while analyzing the nature of invasion of different exotic and indigenous species, that the weed invasion and colonization are greatly influenced by the anthropogenic activities like disturbances by transport vehicles and bull carts (Knight et al., 2005). In fact these activities have been helping seed spread from one place to another. Besides, the prevailing topographical situation like existence of slopes, field edges control the distribution pattern (Anı'bal et al., 2006). In this study an effort has been made to investigate the effect if more than one of those factors are present at a time. Hyptis suaveolens, a weed exotic in India (Sanyal, 1994), and its exploration through the district of Bankura, India and domineering success of establishment over the pre-existing indigenous species in short span of time evoked an interest to study with it. Hyptis has been given importance as noxious in countries like USA (USDA, 2003; USDA, 2010), Australia (Parsons et al., 2001). As per the observation, this species may well be represented as invasive in certain habitats, and not so broad like Chromolaena odorata (Linn.) King \& Robin, in habitat selection (Ambika et al., 1989; Boppré el al., 1994; Kriticos et al., 2005; McFadyen, 2002). Very significantly, land form factors, like slope or plain, disturbed or undisturbed (Buckley, 2007) determine the habitats to be established or preferred for invasion (Keeley et al., 2003). In each unique habitat, growth of each exotic plant may be different depending upon the invasion resistance of the environment to that species (Zardi et al., 2006). In the current study, two landscapes in proximity to roads, in one of which slope along with field edges, were selected. Thus study represents an effort to account factors, namely, field edges and presence of anthropogenic activity in term of nearby roads. Analysis of such factor in tropical dry deciduous vegetation, where naturally growing indigenous annual plant species outnumbered the perennials, (Sanyal, 1994) and where some of the species are having possibilities of loosing habitats by the exotic weeds (Erika et al., 2001; Vitousek, 1988) is essential as to gather information for further management of weeds and to provide conservation to indigenous plant species or existing landscape and habitat forms.

\section{Materials and Methods}

For the current study, two plots (each measuring $60 \mathrm{~m} \times 40 \mathrm{~m}$ ) one in Puranderpur (Plot 1: $23^{\circ}$

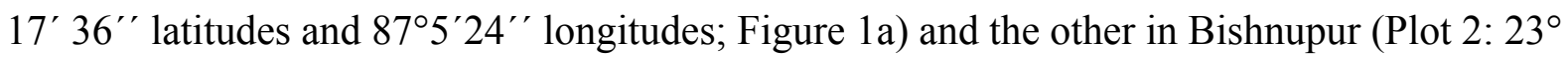
$5^{\prime} 20^{\prime \prime}$ latitudes and $87^{\circ} 17^{\prime} 36^{\prime \prime}$ longitudes; Figure 1b), on National Highway No. 60 (NH 60 ), situated $60 \mathrm{~km}$ apart in the district of Bankura, in West Bengal, India. This district is in a semi arid transitional zone between Gangetic plain and Chhotanagpur Plateau. Both the fields were somehow alike in soil characteristics and classified as flood plain and alluvial fill named 'Kantaban Soil Series No. 3' (ICAR, 1991). The east of Plot 1 and the west side of Plot 2 were attached to National Highway No. 60 ( NH 60) where as west of Plot 1 and of Plot 2 were continuous with unaltered landscape. In the north, Plot 1 was attached to another fallow land forming a field edge due to its slightly lower elevation where as Plot 2 was attached to a seasonal river 'Birai', which again formed a field boundary. The south in Plot 1 was adjacent to a village road with considerable traffic of bull-cart, tractor etc. and that in Plot 2, was attached to a state highway. Thus, except west sides in case of Plot 1 and east in case of Plot 2 
(the sides that continues with unchanged landscape extension), both the fields were surrounded by field edges by other three sides.

The plots were divided into $12 \times 8$ grids (resulting in eight horizontal and twelve vertical strips in each plots) with mildly marked lines in $5 \mathrm{~m}$ gaps horizontally (East-West) and vertically (North-South) thus each block measured 25 sq. m. (Figure 1a \& b). However no physical demarcation was raised inside the fields that could hamper the continuity within the plots. This kind of approach was taken in previous studies (Ngobo et al., 2004).

Data of Hyptis suaveolens population were collected in block wise in the years 2007 and 2008 in order to observe the existing population pattern of the species. In 2008, all plant debris was removed and all stands of Hyptis were eradicated before flowering, in order to remove all the native propagules. The fields were then subjected to fresh re-invasion by Hyptis suaveolens with propagules coming from adjacent areas. From 2009 and up to 2011 data was collected in similar fashion as was done in 2007 and 2008. The growth of population in both of the plots are analysed from yearly total population data and its trend is analysed. Field boundary and boundary side anthropogenic activity are two most significant positive factors for assemblage of weeds (McFadyen, 2007; Rose, 1997). Since both being related with field boundary, in the current study these factors have been together regarded as a Unified Field Edge Factor (UFEF). The study also tried to identify its pattern of influence to reinvasion of Hyptis. The UFEF has been nalyzi as function of distance from the side boundary. Since no two blocks in a plot being of similar status regarding the relative distances from all the edges, comparison between blocks through commonly used parameters like means, standard deviations etc. are not applicable. If there were any effect of field edges that would be unidirectional (in perpendicular direction), and in parallel direction there would be equal and invariant effect throughout. For this purpose the two parameters are taken in the current study. Those are respectively Horizontal Strip Total (HST) and Vertical Strip Total (VST). Each block in a strip may have different distances hence different effects of the adjacent edge(s), but as soon as the strip total is taken as parameter, the effects are automatically shirked. The HST and VST values in each strip for both the plots in every respective year are calculated from block wise collected values. For nalyzing these values, the reference lines are considered to be situated $2.5 \mathrm{~m}$ east from the east edge and $2.5 \mathrm{~m}$ north from the north edge in Plot 1 (Figure 1a); and $2.5 \mathrm{~m}$ west from west edge and $2.5 \mathrm{~m}$ north from the north edge in Plot 2 (Figure 1b). Distance of each strip was represented by the distance of their central lines from the respective lines of reference (Figure 1a \&b) and HSTs and VSTs for every year are assumed functions that of. 

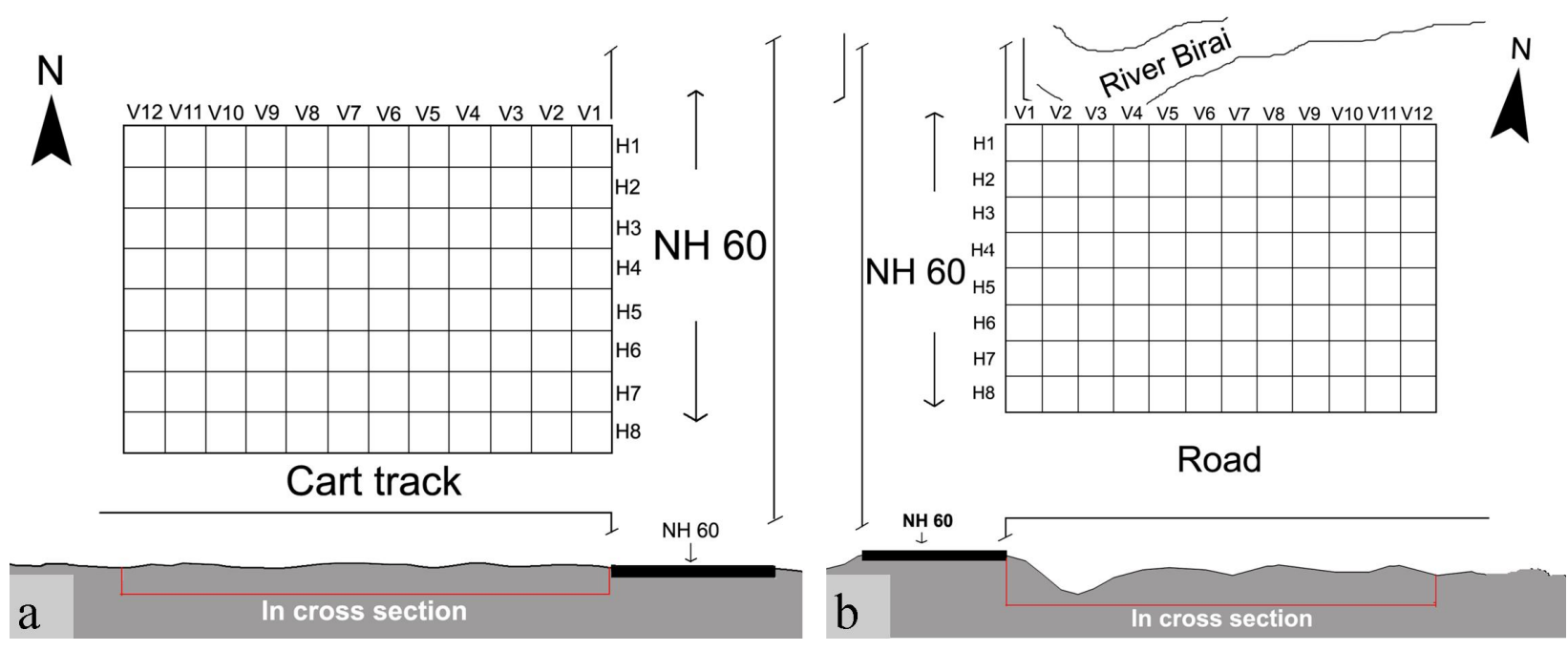

Figure 1. landscape and topography, (a) plot 1, (b) plot 2

\section{Result and Discussions}

\subsection{Descriptive Analysis}

The year wise populations as obtained in each blocks are graphically represented by three dimensional bar graphs (Figure 3 for plot 1) and in (Figure 4 for plot 2). From block-level data, year wise total populations are calculated. Table 1 represents year wise totals for both of the plots.

Table 1. Year wise total population of Hyptis suaveolens in both the plots

\begin{tabular}{|l|l|l|l|}
\hline Plot No. & Year & Total Population & Remark \\
\hline \multirow{4}{*}{} & 2007 & 20667 & Considered saturated \\
\cline { 2 - 4 } & 2008 & 21479 & Considered saturated \\
\cline { 2 - 4 } & 2009 & 2214 & Re-introduction phage \\
\cline { 2 - 4 } & 2010 & 13830 & Rapid colonization \\
\cline { 2 - 4 } & 2011 & 18688 & Approaching to saturation \\
\hline \multirow{4}{*}{2} & 2007 & 20600 & Considered saturated \\
\cline { 2 - 4 } & 2008 & 20190 & Considered saturated \\
\cline { 2 - 4 } & 2009 & 3135 & Re-introduction phage \\
\cline { 2 - 4 } & 2010 & 12690 & Rapid colonization \\
\cline { 2 - 4 } & 2011 & 16481 & Approaching to saturation \\
\hline
\end{tabular}

These values are plotted to represent graphically (Figure $2 \mathrm{a}$ and Figure $2 \mathrm{~b}$ ). Both of the study plots have shown similar behaviour in this regard. The values of first two years (2007 and 2008) i.e. existing natural populations are considered saturated. In very first year after eradication (2009) the growth was slower. Populations of two plots being (2214 and 3135 in Plot 1 and Plot 2 respectively). But in very next year i.e. in 2010, the growth increased tremendously. Populations of two plots being (13830 and 12690 in Plot 1 and Plot 2 respectively). Again in 2011 there was too an incremental growth as the total population of 
two plots (18688 and 16481 in Plot 1 and Plot 2 respectively). But the rate of growth (evident from the steepness of the curves in Figure 2a and Figure 2b) decreased significantly in next year to attain saturation. After eradication i.e. in the year 2009 there was negligible amount of pre-existing propagules in both of the experiment plots, which should have increased in 2010 . The surrounding area of the plots was kept intact throughout the period of experiment. So the increment in population over the subject plots are not mainly dominated by propagules coming from external source, rather by the native propagules, otherwise the total number of plants in first and second year would not have differ. Since there is a rapid growth between 2009 and 2010 over both the plots, it is evident that Hyptis in a new environment increase its population very rapidly. The Figure $2 \mathrm{a}$ and Figure $2 \mathrm{~b}$ show the total growth pattern of both the plots and tendency to saturation in bar diagram format. The tips are connected by line, which shows same sigmoid nature for both of the plots. The three year from 2009 to 2011, shows the three phases of invasion. First year being the phase of invasion, second the colonization and the third, tending to saturation.
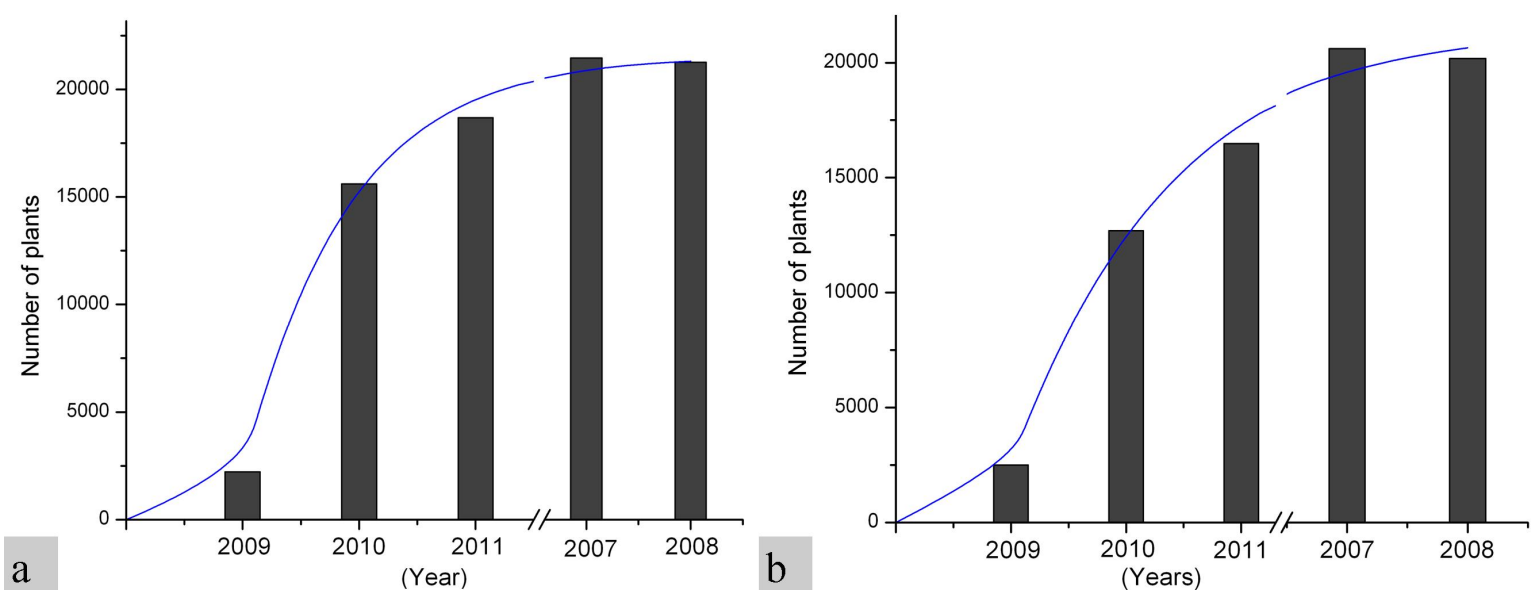

Figure 2. Yearwise total population of Hyptis suaveolens, (a) for plot 1, (b) for plot 2

\subsection{Spatial Analysis}

The year-wise HST and VST values are shown in Table 2 and Table 3 respectively. Distances from corresponding line of references versus HSTs variations are shown in Figure 7 and Figure 8 and VSTs are shown in Figure 5 and Figure 6, respectively for plot 1 and plot 2. Figure 3 and Figure 4 graphically represents block wise populations in different years for both of the plots. 


\section{MInstitute ${ }^{\text {Mnk }}$}
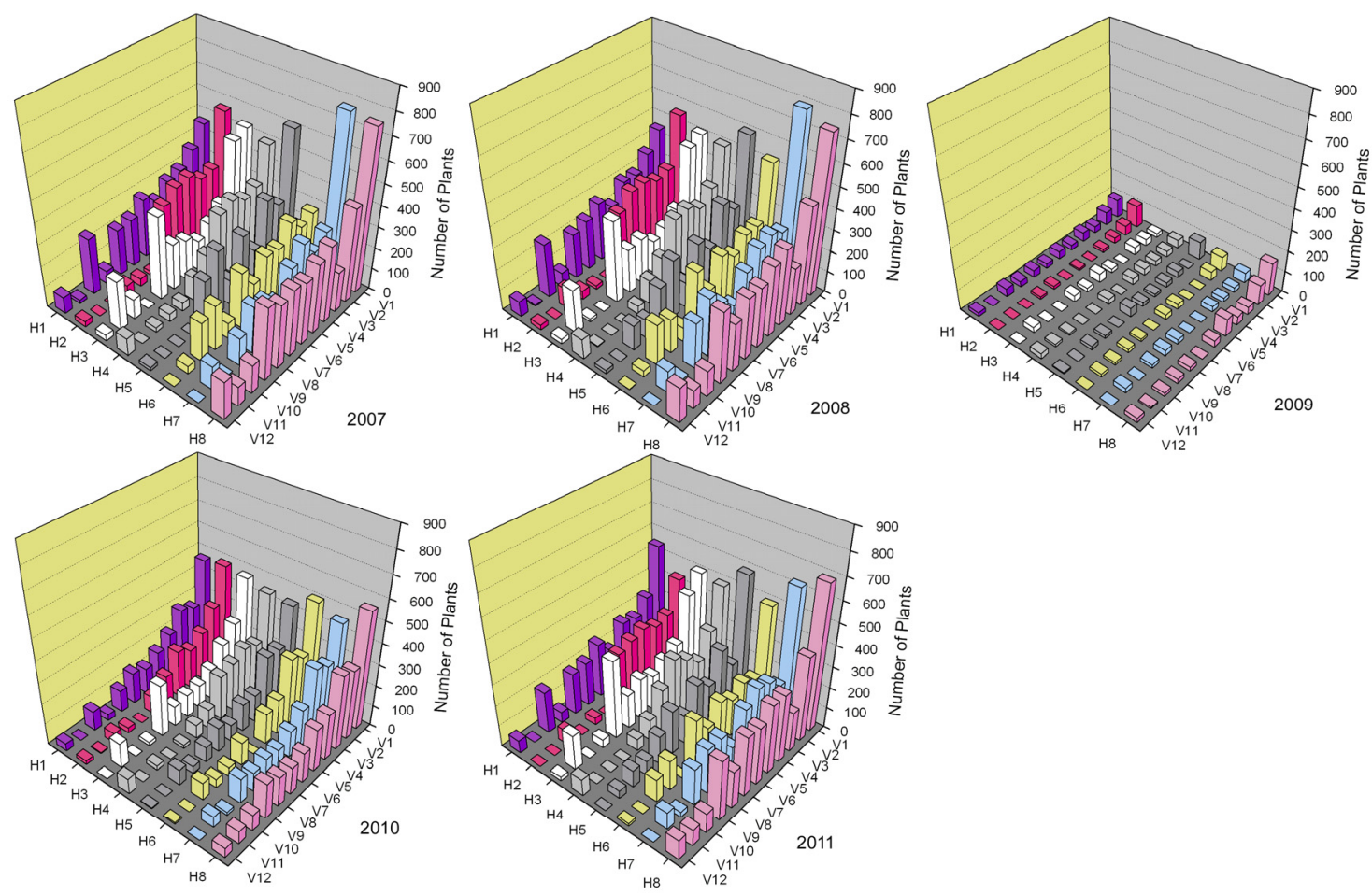

Figure 3. Occurrence of Hyptis suaveolens stands as recorded blockwise in Plot 1 from 2007 to 2011
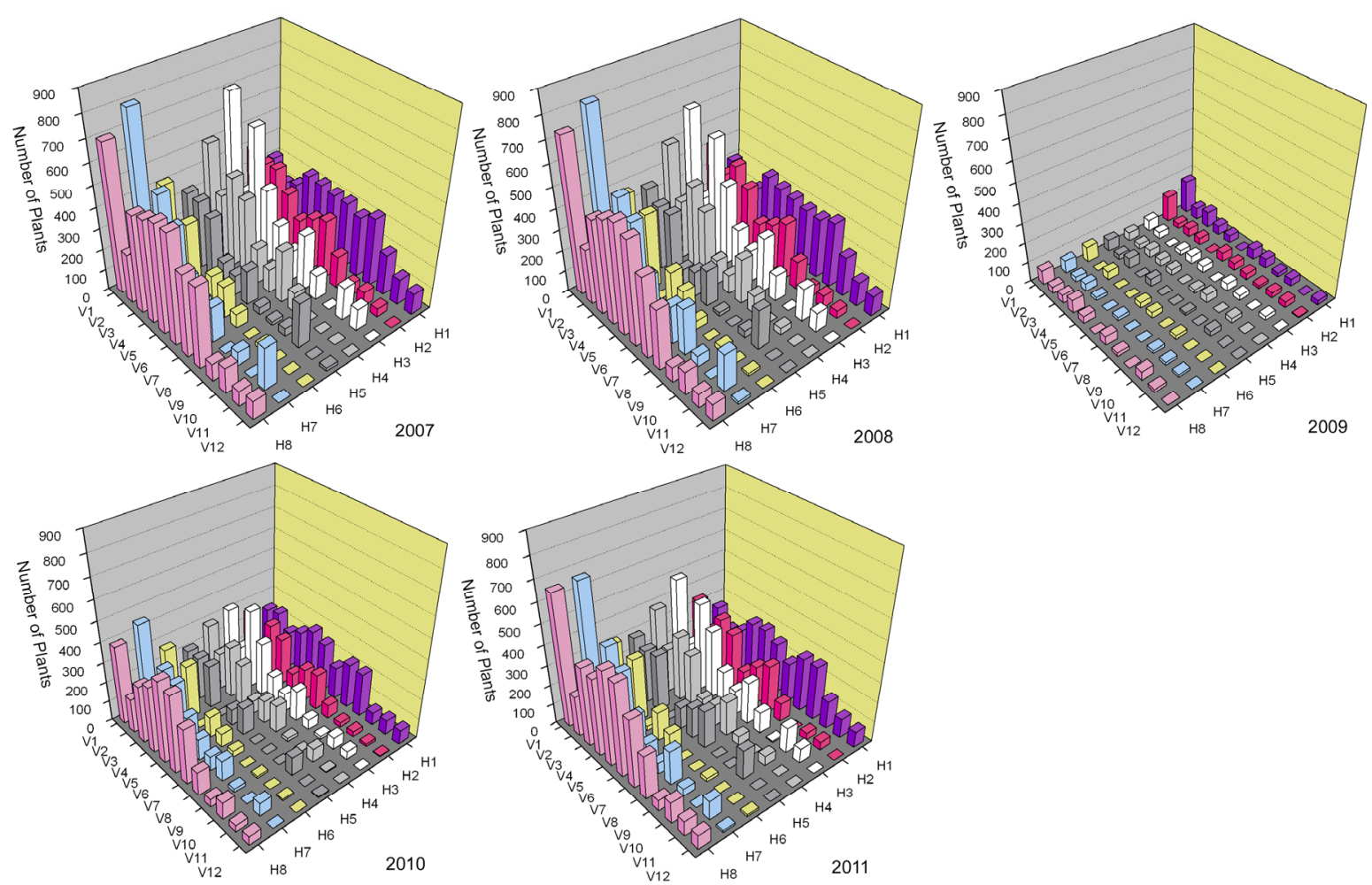

Figure 4. Occurrence of Hyptis suaveolens stands as recorded blockwise in Plot 2 from 2007 to 2011 
Table 2. Vertical strip wise total population of Hyptis suaveolens in two plots for the years from 2007 to 2011

\begin{tabular}{|c|c|c|c|c|c|c|c|c|c|c|c|c|c|}
\hline \multirow{2}{*}{ Plot No. } & \multirow[t]{2}{*}{ Year } & \multicolumn{12}{|c|}{ Strip } \\
\hline & & V1 & V2 & V3 & V4 & V5 & V6 & V7 & V8 & V9 & V10 & V11 & V12 \\
\hline \multirow{5}{*}{1} & 2007 & 3986 & 2807 & 2278 & 2267 & 2166 & 1665 & 1650 & 1497 & 833 & 708 & 396 & 414 \\
\hline & 2008 & 4667 & 2854 & 2336 & 2241 & 2150 & 1644 & 1609 & 1421 & 910 & 797 & 449 & 401 \\
\hline & 2009 & 519 & 330 & 203 & 176 & 194 & 179 & 128 & 137 & 106 & 92 & 83 & 67 \\
\hline & 2010 & 3814 & 2279 & 1465 & 1433 & 1302 & 829 & 767 & 705 & 423 & 405 & 232 & 176 \\
\hline & 2011 & 4353 & 2379 & 1965 & 2019 & 1956 & 1560 & 1375 & 1165 & 742 & 562 & 358 & 254 \\
\hline \multirow{5}{*}{2} & 2007 & 4136 & 2235 & 3217 & 2350 & 1893 & 1809 & 1778 & 1061 & 594 & 767 & 552 & 208 \\
\hline & 2008 & 4149 & 1998 & 3227 & 2374 & 1893 & 1833 & 1561 & 1152 & 547 & 751 & 511 & 194 \\
\hline & 2009 & 858 & 286 & 421 & 279 & 212 & 152 & 226 & 236 & 119 & 198 & 101 & 47 \\
\hline & 2010 & 2401 & 1283 & 2181 & 1546 & 1323 & 1304 & 1009 & 579 & 322 & 389 & 233 & 120 \\
\hline & 2011 & 3378 & 1585 & 2708 & 1933 & 1589 & 1477 & 1402 & 892 & 383 & 594 & 374 & 166 \\
\hline
\end{tabular}

Table 3. Horizontal strip wise total population of Hyptis suaveolens in two plots for the years from 2007 to 2011

\begin{tabular}{|l|l|l|l|l|l|l|l|l|l|}
\hline \multirow{2}{*}{ Plot No. } & Year & \multicolumn{9}{|c|}{ Strip } \\
\cline { 3 - 10 } & & H1 & H2 & H3 & H4 & H5 & H6 & H7 & H8 \\
\hline \multirow{4}{*}{1} & 2007 & 2716 & 2267 & 2960 & 2213 & 2290 & 2169 & 2448 & 3604 \\
\cline { 2 - 11 } & 2008 & 2795 & 2360 & 2968 & 2175 & 2546 & 2447 & 2775 & 3413 \\
\cline { 2 - 11 } & 2009 & 415 & 207 & 238 & 210 & 240 & 206 & 192 & 506 \\
\cline { 2 - 11 } & 2010 & 1833 & 1650 & 1718 & 1546 & 1510 & 1590 & 1720 & 2263 \\
\cline { 2 - 11 } & 2011 & 2574 & 1946 & 2488 & 1989 & 2181 & 1902 & 2435 & 3173 \\
\hline \multirow{5}{*}{2} & 2007 & 3088 & 2469 & 2957 & 2231 & 1614 & 1362 & 2804 & 4075 \\
\cline { 2 - 11 } & 2008 & 2914 & 2418 & 2838 & 2037 & 1793 & 1316 & 2902 & 3972 \\
\cline { 2 - 10 } & 2009 & 572 & 427 & 447 & 250 & 216 & 192 & 421 & 610 \\
\cline { 2 - 10 } & 2010 & 2189 & 1426 & 1693 & 1340 & 951 & 849 & 1677 & 2565 \\
\cline { 2 - 10 } & 2011 & 2509 & 1866 & 2293 & 1667 & 1434 & 1058 & 2266 & 3388 \\
\hline
\end{tabular}

For both of the plots, there had been a specific trend of declination in values of VSTs away from only attached field edge (which is along NH60). For HST values, the graphs take ' $U$ ' shapes. 


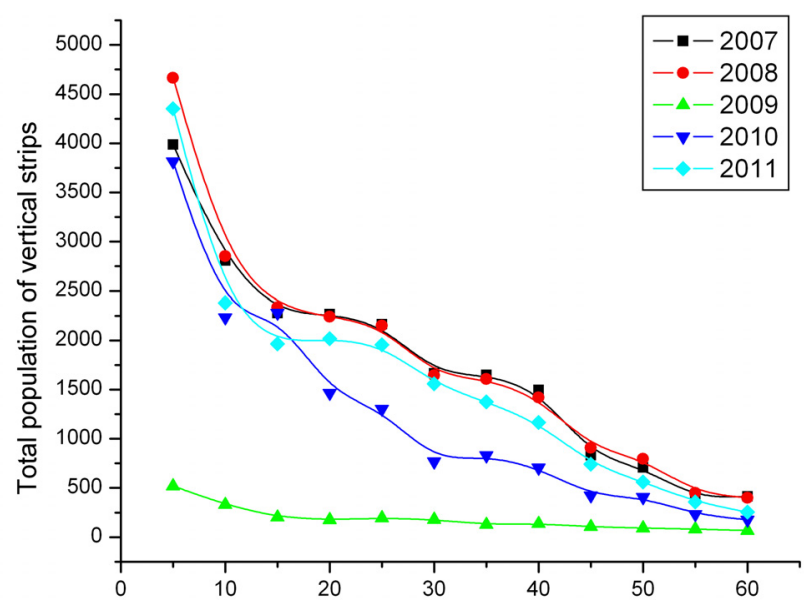

Figure 5. Distance v/s vertical strip total population of Hyptis suaveolen (yearwise plotting) for Plot 1

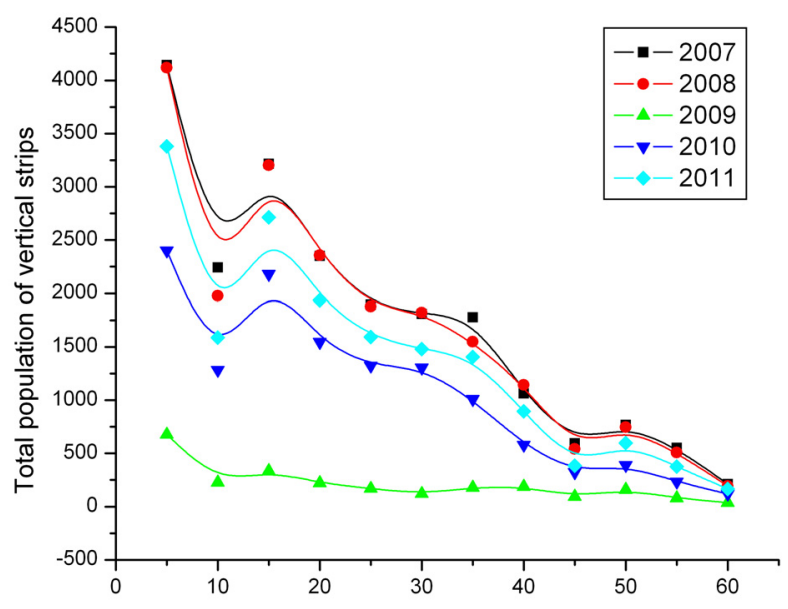

Figure 6. Distance v/s vertical strip total population of Hyptis suaveolen (yearwise plotting) for Plot 2

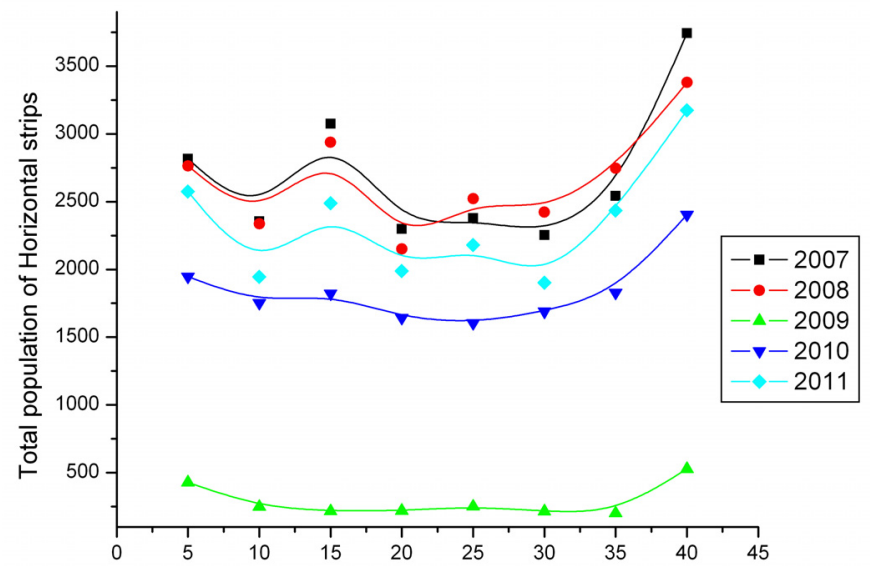

Figure 7. Distance v/s horizontal strip total population of Hyptis suaveolen (yearwise plotting) for Plot 1 


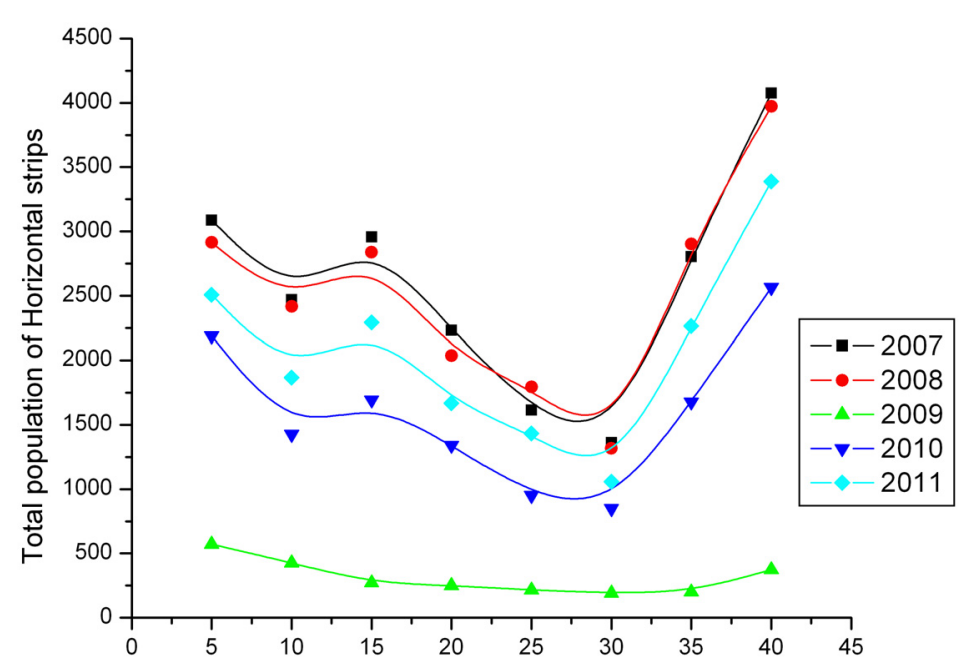

Figure 8. Distance v/s horizontal strip total population of Hyptis suaveolen (yearwise plotting) for Plot 2

It is mentioned that unlike horizontal strips, all the vertical strips attached to two field edges by their both ends. This indicates the positive influence of proximity to UFEF on Hyptis population by its both lateral edges. Since the horizontal strips are attached to field edge by only one edge, for the variation in VSTs with respect to distance from a given UFEF (x) are regressed in exponential regression (Table 4).

Table 4. Regression equations of variation of VSTs with respect to distance from UFEF (x)

\begin{tabular}{|c|l|l|l|}
\hline Plot & Year & Regression Equation & $\mathbf{R}^{\mathbf{2}}$ \\
\hline \multirow{4}{*}{$\mathbf{1}$} & 2007 & $\mathrm{VST}=5040.2 \mathrm{e}^{-0.0397 \mathrm{x}}$ & 0.9241 \\
\cline { 2 - 4 } & 2008 & $\mathrm{VST}=5218.9 \mathrm{e}^{-0.0398 \mathrm{x}}$ & 0.941 \\
\cline { 2 - 4 } & 2009 & $\mathrm{VST}=426.9 \mathrm{e}^{-0.031 \mathrm{x}}$ & 0.9181 \\
\cline { 2 - 4 } & 2010 & $\mathrm{VST}=4082.5 \mathrm{e}^{-0.0499 \mathrm{x}}$ & 0.9702 \\
\cline { 2 - 4 } & 2011 & $\mathrm{VST}=5042.9 \mathrm{e}^{-0.0446 \mathrm{x}}$ & 0.9289 \\
\hline \multirow{4}{*}{2} & 2007 & $\mathrm{VST}=5591.6 \mathrm{e}^{-0.0449 \mathrm{x}}$ & 0.8795 \\
\cline { 2 - 4 } & 2008 & $\mathrm{VST}=5543.4 \mathrm{e}^{-0.0456 \mathrm{x}}$ & 0.8673 \\
\cline { 2 - 4 } & 2009 & $\mathrm{VST}=641 \mathrm{e}^{-0.0351 \mathrm{x}}$ & 0.7499 \\
\cline { 2 - 4 } & 2010 & $\mathrm{VST}=3808.3 \mathrm{e}^{-0.0496 \mathrm{x}}$ & 0.8841 \\
\cline { 2 - 4 } & 2011 & $\mathrm{VST}=4604.4 \mathrm{e}^{-0.0466 \mathrm{x}}$ & 0.8629 \\
\hline
\end{tabular}

For plot $1, \mathrm{R}^{2}$ values are above 0.9 every year, where as that for plot 2 those being above 0.8 in almost all cases. Very significantly, the values of coefficients of ' $\mathrm{x}$ ' in exponents are also similar (near about $0.04 \mathrm{~m}^{-1}$ ) in different cases. The relatively lesser $\mathrm{R}^{2}$ value in plot 2 is due to slight irregular trend in VST values in between $1^{\text {st }}, 2^{\text {nd }}$ and $3^{\text {rd }}$ vertical strips in every year (Figure 4 and Figure 6). The value decreases in the $2^{\text {nd }}$ strips with respect to $1^{\text {st }}$, and again increases in third. This may be due to the undulated landscape of plot 2, as evident from Figure 1, where the first three strips form a valley like channel. The $1^{\text {st }}$ and the $3^{\text {rd }}$ strips being the two sloppy sides where as, the $2^{\text {nd }}$ being a flat base in between. The out come resembles 


\section{Macrothink}

the previous studies, which suggests valley slopes home more assemblage than the base (Ann Gayek et al. 2001).

\subsection{Fourier Frequency Analysis}

In order to analyse the pattern of influence of UFEF more properly Fourier transformation is applied over the special variations of HSTs (along vertical direction) and VSTs (along horizontal direction) data to arrive at frequency domain spectra for both of the plots. For both of the plots the frequencies versus phase spectra for different years in any direction (horizontal or vertical) are almost identical. The amplitude spectra get magnified through the years after eradication, maintaining similarities in patterns. (Figure 9 and Figure 10). This indicates that the effects us UFEF has a regular and invariant proportionate trend of spatial variability through the years.
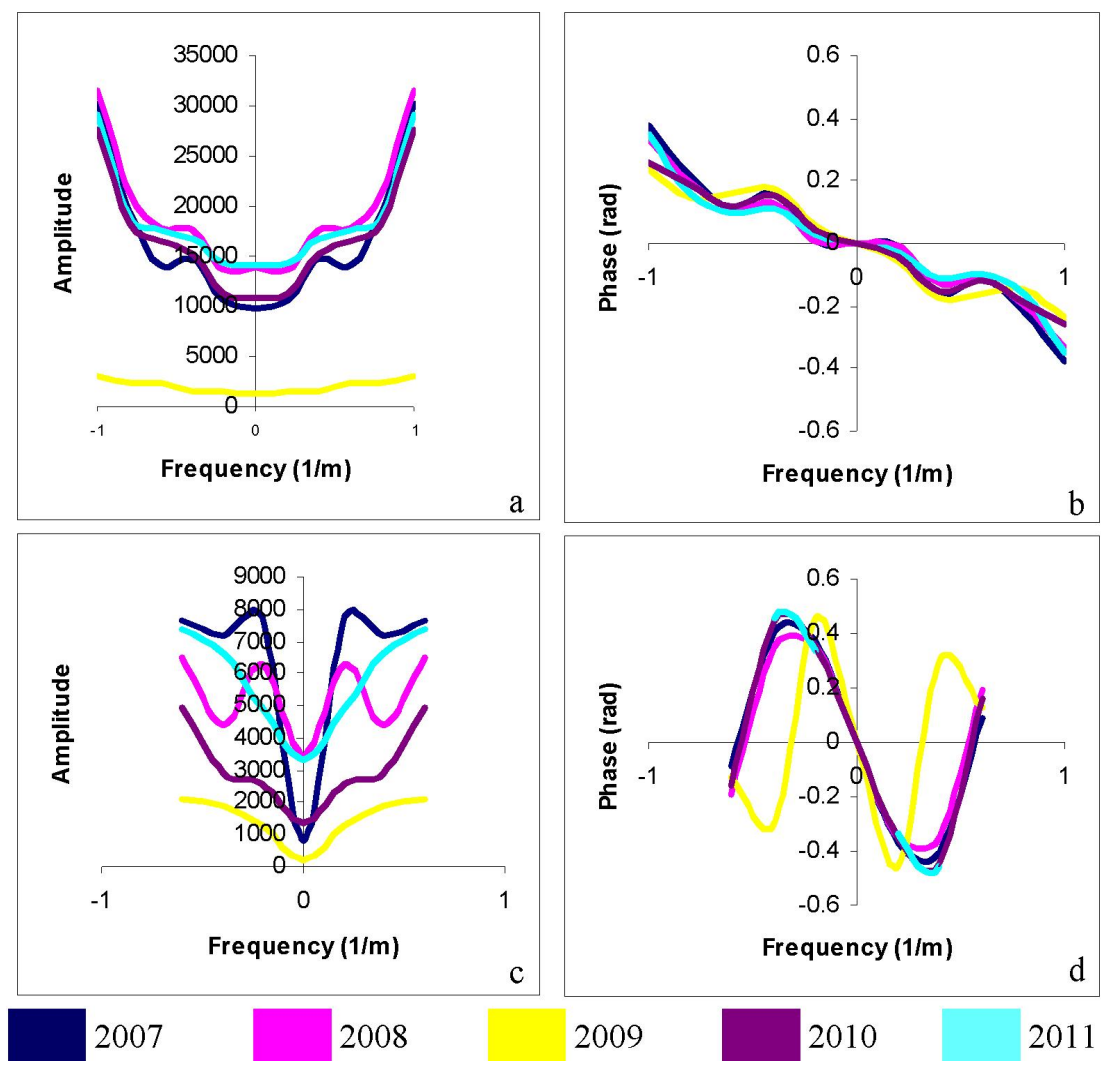

Figure 9. Frequency analysis for plot 1 ; a \& b along horizontal direction, c \& d along vertical direction 

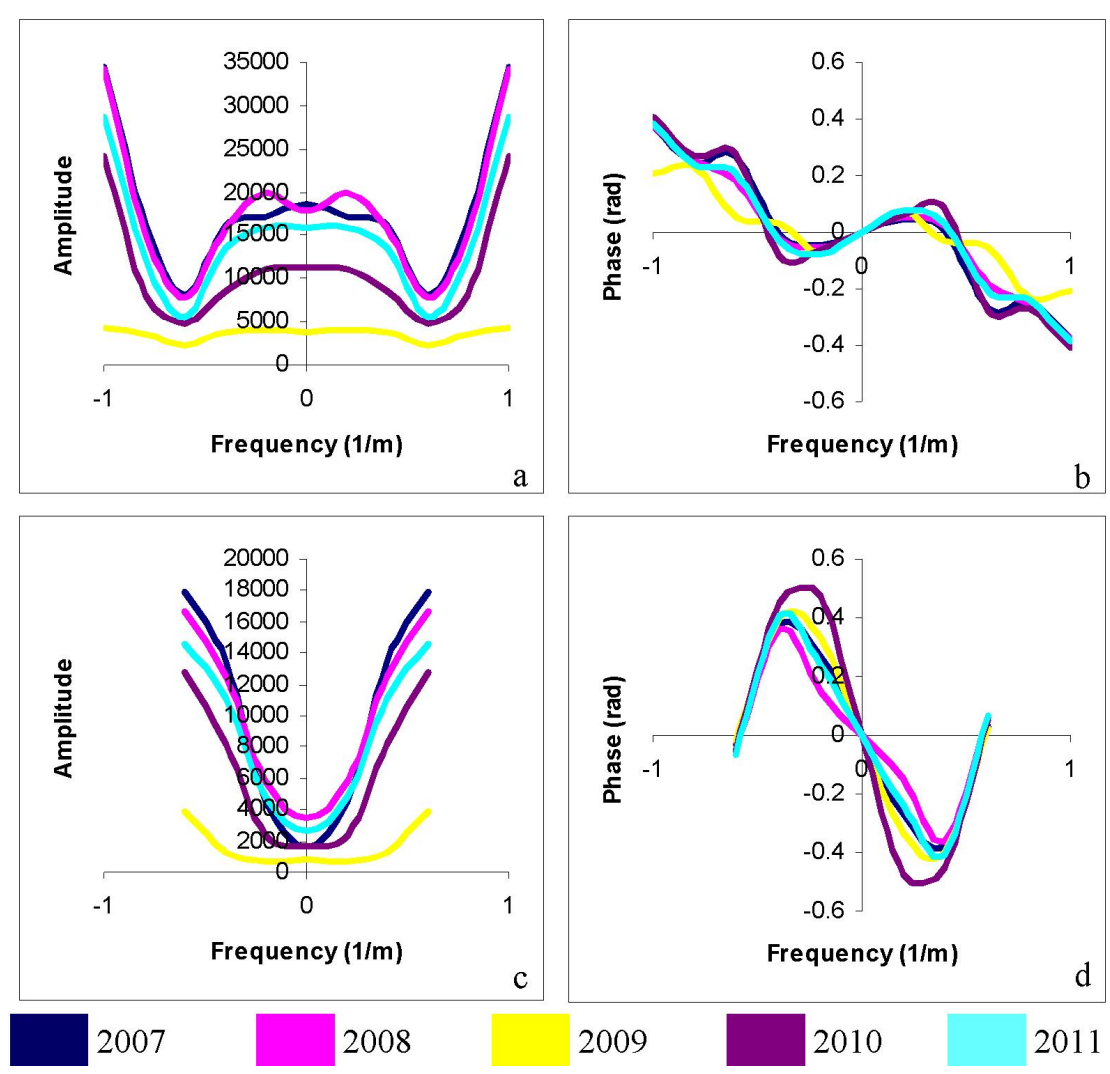

Figure 10. Frequency analysis for plot 2; a \& b along horizontal direction, $\mathrm{c} \& \mathrm{~d}$ along vertical direction

\subsection{Correlation Analysis}

A statistical correlation analysis is done over the year wise HSTs and VSTs for both of the plots (Table 5 to Table 8). In all the cases the analyses have shown high correlation values for all strips, indicating regularity in occurrence of strip total at any spatial point correlative to other strips, irrespective of year. This once again signifies another property of spatial characteristics of UFEF which acts similarly for both HSTs and VSTs.

Table 5. Correlation analysis on HSTs for plot 1

\begin{tabular}{llllll}
\hline & $\mathbf{2 0 0 7}$ & $\mathbf{2 0 0 8}$ & $\mathbf{2 0 0 9}$ & $\mathbf{2 0 1 0}$ & $\mathbf{2 0 1 1}$ \\
\hline $\mathbf{2 0 0 7}$ & 1 & & & & \\
$\mathbf{2 0 0 8}$ & 0.946477 & 1 & & & \\
$\mathbf{2 0 0 9}$ & 0.828275 & 0.75478 & 1 & & \\
$\mathbf{2 0 1 0}$ & 0.924911 & 0.878683 & 0.883908 & 1 & \\
$\mathbf{2 0 1 1}$ & 0.951562 & 0.954591 & 0.849562 & 0.916935 & 1 \\
\hline
\end{tabular}


Table 6. Correlation analysis on HSTs for plot 2

\begin{tabular}{llllll}
\hline & $\mathbf{2 0 0 7}$ & $\mathbf{2 0 0 8}$ & $\mathbf{2 0 0 9}$ & $\mathbf{2 0 1 0}$ & $\mathbf{2 0 1 1}$ \\
\hline $\mathbf{2 0 0 7}$ & 1 & & & & \\
$\mathbf{2 0 0 8}$ & 0.989423 & 1 & & \\
$\mathbf{2 0 0 9}$ & 0.941145 & 0.930744 & 1 \\
$\mathbf{2 0 1 0}$ & 0.977163 & 0.958235 & 0.957109 & 1 \\
$\mathbf{2 0 1 1}$ & 0.990782 & 0.993518 & 0.933737 & 0.977734 & 1 \\
\hline
\end{tabular}

Table 7. Correlation analysis on VSTs for plot 1

\begin{tabular}{llllll}
\hline & $\mathbf{2 0 0 7}$ & $\mathbf{2 0 0 8}$ & $\mathbf{2 0 0 9}$ & $\mathbf{2 0 1 0}$ & $\mathbf{2 0 1 1}$ \\
\hline $\mathbf{2 0 0 7}$ & 1 & & & & \\
$\mathbf{2 0 0 8}$ & 0.991061 & 1 & & & \\
$\mathbf{2 0 0 9}$ & 0.935284 & 0.966254 & 1 & & \\
$\mathbf{2 0 1 0}$ & 0.955688 & 0.969646 & 0.943914 & 1 & \\
$\mathbf{2 0 1 1}$ & 0.984751 & 0.99693 & 0.964171 & 0.966782 & 1 \\
\hline
\end{tabular}

Table 8. Correlation analysis on VSTs for plot 2

\begin{tabular}{llllll}
\hline & $\mathbf{2 0 0 7}$ & $\mathbf{2 0 0 8}$ & $\mathbf{2 0 0 9}$ & $\mathbf{2 0 1 0}$ & $\mathbf{2 0 1 1}$ \\
\hline $\mathbf{2 0 0 7}$ & 1 & & & & \\
$\mathbf{2 0 0 8}$ & 0.996586 & 1 & & & \\
$\mathbf{2 0 0 9}$ & 0.891884 & 0.897285 & 1 \\
$\mathbf{2 0 1 0}$ & 0.986561 & 0.988217 & 0.823164 & 1 \\
$\mathbf{2 0 1 1}$ & 0.996496 & 0.998486 & 0.887961 & 0.990458 & 1 \\
\hline
\end{tabular}




\section{Conclusion}

A spatiotemporal analysis of distribution pattern of Hyptis has been addressed in the current study. The variation of Hyptis population away from UFEF is expressed in terms of regressed equations. Pattern of variation is also analysed through Fourier frequency analysis and correlation analysis. In all cases regularity in pattern irrespective of time is observed. Albeit the values have been magnified posterior to eradication, the mutual relationships between horizontal and vertical strips, i.e. in term of spatial difference with respect to UFEF remained qualitatively invariant.

\section{Reference}

Ambika, S. R., \& Jayachandra (1989). The Problem of Chromolaena Weed. Newsletter: Chromolaena odorata, Biological Control Newsletter, 3, 1-6, Charles Darwin University, Australia

Boppré M., \& Fischer O.W. (1994). Zonocerus and Chromolaena in West Africa, a chemoecological approach towards pest management. In S. Krall \& H. Wilps (Eds). New Trends in Locust Control (pp. 107-126). D-Eschborn: GTZ

Buckley, Y. M., Bolker, B. M., \& Rees, M. (2007). Disturbance, invasion and re-invasion: managing the weed-shaped hole in disturbed ecosystems. Ecology Letters, 10(9), 809-817. http://dx.doi.org/10.1111/j.1461-0248.2007.01067.x

Erika, S. Z, Richard, J. H., \& Harold, A.,M. (2001). Viewing invasive species removal in a whole-ecosystem context. Trends in Ecology \& Evolution, 16(8), 454-459. http://dx.doi.org/10.1016/S0169-5347(01)02194-2

Keeley, J.E., Lubin, D \& Fotheringham C.J. (2003). Fire and grazing impacts on plant diversity and alien plant invasions in the southern Sierra Nevada. Ecological Applications, 13(5), 1355-1374. http://dx.doi.org/10.1890/02-5002

Knight, K. S., \& Peter B. R., (2005). Opposite relationships between invasibility and native species richness at patch versus landscape scales. Oikos, 109(1), 81-88(8). http://dx.doi.org/10.1111/j.0030-1299.2005.13639.x

Kriticos D. J., Yonow T., \& Mcfadyen R. E. C. (2005). The potential distribution of Chromolaena odorata (Siam weed) in relation to climate. Weed Research, 45(4), 246-254. http://dx.doi.org/10.1111/j.1365-3180.2005.00458.x

McFadyen, R. E. C. (2002). Chromolaena in Asia and the Pacific: spread continues but control prospects improve. In: Zachariades, C., Muniappan, R. \& Strathie, L.W. (Eds), Proceedings of the Fifth International Workshop on Biological Control and Management of Chromolaena odorata, Durban.

Ngobo, M., McDonald, M., \& Weise S. (2004). Impacts of Type of Fallow and Invasion by Chromolaena odorata on Weed Communities in Crop Fields in Cameroon Ecology and Society. 9 (2), Art. 15. [Online] Available: http://www.ecologyandsociety.org/vol9/iss2/art1 (August 23, 2012) 


\section{Macrothink}

Journal of Environment and Ecology

ISSN 2157-6092 2012, Vol. 3, No. 1

Parsons W. T., \& Cuthbertson, E. G. (2001). Noxious Weeds of Australia. (2 ${ }^{\text {nd }}$ ed) CSIRO Publishing. P. 10.

Pauchard, A., \& Alaback, P.B. (2006). Edge type defines alien plant species invasions along Pinus contorta burned, highway and clearcut forest edges. Forest Ecology and Management, 223, 327-335. http://dx.doi.org/10.1016/j.foreco.2005.11.020

Rose, S. (1997). Influence of suburban edges on invasion of Pittosporum undulatum into the bushland of northern Sydney, Australia. Austral Ecology, 22(1), 89-99. http://dx.doi.org/10.1111/j.1442-9993.1997.tb00644.x

Sanyal, M. N. (1994). Flora of Bankura District. (W.B). (p.360). Bishen Singh Mahendra Pal Singh.

Sanyal, M. N. (1994). Flora of Bankura District. (W.B). (pp.495-521). Bishen Singh Mahendra Pal Singh.

SOILS (Map). Bankura District, West Bengal, (1991) Indian Council of Agricultural Research (ICAR).

USDA (2003). State noxious weed seed requirements recognized in administration at the federal seed act.

USDA (2010). State noxious weed seed requirements recognized in administration at the federal seed act.

Vitousek, P. M. (1988). Diversity and biological invasions of oceanic islands. In Wilson, E.O. (ed.), BioDiversity. (p. 181-189). National Academy Press.

Zardi, G. I., Nicastro, K. R., Porri, F., \& McQuaid, C. D. (2006). Sand stress as a non-determinant of habitat segregation of indigenous (Perna perna) and invasive (Mytilus galloprovincialis) mussels in South Africa. Marine Biology, 148(5), 1031-1038. http://dx.doi.org/10.1007/s00227-005-0155-6 